\title{
Preparation and Characterization of High Activity Zirconium-Doped Anatase Titania for Solar Photocatalytic Degradation of Ethidium Bromide
}

\author{
S. SWETHA, R. GEETHA BALAKRISHNA* \\ Nanobiosciences, Center for Emerging Technologies, Jain University, Ramanagara, Bangalore-562112, India
}

\begin{abstract}
Ethidium bromide is a fluorescent tag and is used in biomedical applications. It is a potent mutagen because of its DNA intercalating nature. A catalyst composition for the feasible elimination of ethidium bromide using a broad spectrum of solar radiation was investigated. Nanostructured anatase $\mathrm{TiO}_{2}$ was synthesized by gel to crystalline conversion and its bandgap was engineered by doping with zirconium to effectively harness sunlight. The doped nanocrystals were characterized by X-ray diffraction, scanning electron microscopy, transmission electron microscopy, energy dispersive X-ray analysis, and UV-Vis spectroscopy. The formed crystals retained the anatase phase with a marginal increase in size. The pulverization process used to dope $\mathrm{Zr}$ into titania resulted in a nano and doped lattice with an increased and extended light absorption range, which gave a nearly five-fold increase in photoactivity over pure titania. The catalytic effect of the modified titania, the dopant concentration, and the dynamics of the dopant concentration on the charge carriers (trapping-recombination) for the degradation of the mutagen was investigated. The modified titania is capable of total ethidium bromide elimination in sunlight. The loss of its mutagenic property was confirmed by an Ames test. The induced revertant colonies observed were nil in the treated sample indicating a complete loss of the intercalating property of the mutagen.
\end{abstract}

Key words: sunlight; titania; zirconium; ethidium bromide; elimination

CLC number: O643 Document code: A

Received 27 October 2010. Accepted 13 January 2011.

*Corresponding author. Tel: +91-8027577200; Fax: +91-8027577211; E-mail: geethabalakrishna@yahoo.co.in, rgb@jaingroup.info

English edition available online at Elsevier ScienceDirect (http://www.sciencedirect.com/science/journal/18722067).

Ethidium bromide (EtBr, 3,8-diamino-6-phenyl-5-ethyl phenanthridine bromide) is aromatic, and has a tricyclic structure with aniline on either side of pyridine. The ring of $\mathrm{EtBr}$ is hydrophobic and resembles the ring of DNA bases. It is capable of forming close Van der Waals contacts with the base pairs and thereby binding to the hydrophobic interior of the DNA molecule. EtBr intercalates into the compact array of stacked bases, which is responsible for its mutagenic property and its mutagenicity is well established and can be confirmed by the Ames test [1-4].

The highly visible fluorescent complexes formed by such an intercalation make EtBr staining the most popular technique to detect large fragments of RNA/DNA in biomedical applications. The disposal of the fluorescent complexes containing $\mathrm{EtBr}$ is thus a serious area of concern and hence necessitates research into the area of EtBr elimination [5-7]. Compared to regular treatment approaches such as incineration [8], bleaching [9], and irradiation, photocatalysis has a number of advantages including high oxidation efficiency [10], complete degradation, treatment at low pollutant concentration levels, and insignificant product toxicity levels. The most important advantage, however, is the harnessing of an economical, eco-friendly, and abundantly available renewable source of energy. In photocatalysis, the catalyst absorbs photons and this leads to the excitation of electrons from the valence band to the conduction band, which generates electron-hole pairs. The electrons in the conduction band are captured by oxygen molecules that are dissolved in the suspension and the holes in the valence band can be captured by the $\mathrm{H}_{2} \mathrm{O}$ or $\mathrm{OH}^{-}$species that are adsorbed on the surface of the catalyst to produce hydroxyl radicals. These photocatalyst mediated reactions cause the generation of a number of reactive oxygen species (ROS) and $\mathrm{OH}$ radicals with a redox potential of $2.8 \mathrm{eV}$ versus the normal hydrogen electrode. These hydroxyl radicals are very potent oxidants $[11,12]$ and (having high levels of reactivity and being nonselective) can readily initiate oxidation resulting in the elimination of EtBr molecules, as shown in the Scheme 1.

$\mathrm{TiO}_{2}$ is considered to be an able photocatalyst for UV applications because it is relatively safe, has a large bandgap and is stable to photocorrosion [13-16]. In its unmodified form it is highly inefficient in visible light applications. The addition of transition metal ions like $\mathrm{Au}$ [17], $\mathrm{Ag}$ [18], and Mo [19] into the $\mathrm{TiO}_{2}$ lattice increases the rate of photo- 


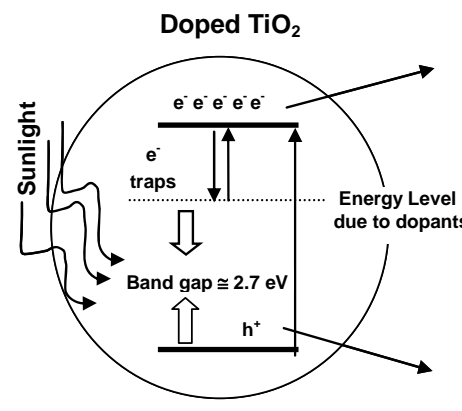

$\mathrm{TiO}_{2}(\mathrm{e})+\mathrm{O}_{2} \rightarrow \mathrm{TiO}_{2}+\mathrm{O}^{-}$

$\mathrm{TiO}_{2}\left(\mathrm{e}^{-}\right)+\cdot \mathrm{O}^{-}{ }_{2}+2 \mathrm{H}^{+} \rightarrow \mathrm{TiO}_{2}+\mathrm{H}_{2} \mathrm{O}_{2}$,

$\mathrm{TiO}_{2}\left(\mathrm{e}^{-}\right)+\mathrm{H}_{2} \mathrm{O}_{2} \rightarrow \mathrm{TiO}_{2}+{ }^{\cdot} \mathrm{OH}+\mathrm{OH}^{-}$

$\mathrm{O}^{-}{ }_{2}+\mathrm{H}_{2} \mathrm{O}_{2} \rightarrow \cdot \mathrm{OH}+\mathrm{OH}^{-}+\mathrm{O}_{2}$,

$\mathrm{O}^{-}{ }_{2}+\mathrm{H}^{+} \rightarrow \cdot \mathrm{HO}_{2}$

$\mathrm{TiO}_{2}(\mathrm{e})+{ }^{-} \mathrm{HO}_{2} \rightarrow \mathrm{TiO}_{2}+\mathrm{HO}_{2}^{-}$,

$\mathrm{HO}_{2}^{-}+\mathrm{H}^{+} \rightarrow \mathrm{H}_{2} \mathrm{O}_{2}$

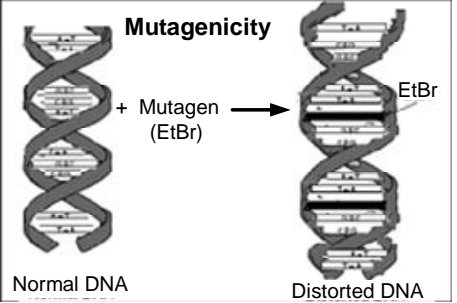

$\mathrm{TiO}_{2}\left(\mathrm{~h}^{+}\right)+\mathrm{H}_{2} \mathrm{O}_{\text {ads }} \rightarrow \mathrm{TiO}_{2}+{ }^{\cdot} \mathrm{OH}_{\text {ads }}+\mathrm{H}^{+}$,

$\mathrm{TiO}_{2}\left(\mathrm{~h}^{+}\right)+2 \mathrm{H}_{2} \mathrm{O}_{\text {ads }} \rightarrow \mathrm{TiO}_{2}+2 \mathrm{H}^{+}+\mathrm{H}_{2} \mathrm{O}_{2}$,

$\mathrm{TiO}_{2}\left(\mathrm{~h}^{+}\right)+\mathrm{OH}^{-}$ads $\rightarrow \mathrm{TiO}_{2}+\cdot \mathrm{OH}_{\text {ads. }}$.

COMPLETE LOSS OF

MUTAGENIC PROPERTY

Scheme 1. Schematic changes in the electronic levels of the modified $\mathrm{TiO}_{2}$ and the role of the ROS produced by the visible light induced photocatalyst in the detoxification of EtBr. Inset: Intercalation of EtBr into DNA, which shows its mutagenic ability.

catalytic oxidation in sunlight. Additionally, the incorporation of transition metal ions into the $\mathrm{TiO}_{2}$ lattice increases the thermal stability of the anatase phase, increases its surface acidity and also increases the rate of formation of $\mathrm{OH}^{-}$ radicals [20]. The incorporation of isovalent zirconium ions into the lattice of $\mathrm{TiO}_{2}$ has been attempted by various techniques and a literature survey indicates that photoactivity is generally enhanced [21-24].

We thus investigated the incorporation of zirconium into $\mathrm{TiO}_{2}$ by pulverization to cause the alteration and possible enhancement of its physical properties. This induces changes in its electronic structure by nanosize and surface effects for the effective absorption of a broader spectrum of sunlight, which results in a higher number of reactive oxygen species and an improved elimination property.

\section{Experimental}

\subsection{Synthesis}

A fine grained powder of the anatase form of $\mathrm{TiO}_{2}$ was prepared by gel to crystalline conversion [25]. Metal substituted $\mathrm{TiO}_{2}$ was prepared by a solid state technique using the precursor, $\mathrm{ZrOCl}_{2} \cdot 8 \mathrm{H}_{2} \mathrm{O}$, to produce a $\mathrm{Zr}$-doped $\mathrm{TiO}_{2}$. The pulverizing mixture for the preparation of the $1 \%$ Zr-doped $\mathrm{TiO}_{2}$ contained a $\mathrm{TiO}_{2}$ (anatase phase) and zirconium oxychloride in a mole ratio of 0.99:0.01 to form the corresponding doped sample with a composition of $\mathrm{Ti}_{0.99^{-}}$ $\mathrm{Zr}_{0.01} \mathrm{O}_{2}$. Pulverization was performed over an optimum time of 90 min to obtain $5 \mathrm{~g}$ of $1 \%$ doped photocatalyst in a Spex $8000 \mathrm{M}$ mixer mill with a tungsten carbide vial. The annealing temperature was $600{ }^{\circ} \mathrm{C}$ and the annealing time was $6 \mathrm{~h}$. A similar procedure was used to dope with differ- ent concentrations of the dopant but with a proportionate increase in the annealing and pulverization time. Repeated pulverization and annealing resulted in effective doping.

\subsection{Characterization}

The prepared compositions were characterized by phase identification using X-ray diffraction (XRD) patterns recorded by a Shimadzu X-ray diffractometer (model XRD 7000 ) with $\mathrm{Cu} K_{\alpha}$ radiation at a scan rate of $1 \% \mathrm{~min}$. The crystallite size and the lattice parameters were obtained by the following equations

$$
\begin{gathered}
d_{h k l}=\frac{\lambda}{\beta \operatorname{Cos} \theta} \\
\frac{1}{d^{2}}=\frac{h^{2}}{a^{2}}+\frac{k^{2}}{b^{2}}+\frac{l^{2}}{c^{2}}
\end{gathered}
$$

where $d_{h k l}$ is the distance between the crystal planes of $h k l, \lambda$ is the wavelength of the X-rays used, $h k l$ are the crystal plane indices, and $a, b$, and $c$ are the lattice parameters. The particle sizes were determined using a transmission electron microscope (Technai 10 Philips TEM microscope). The absorption spectra were recorded using a Shimadzu 1650 PC UV-Vis spectrophotometer for micromolar suspensions of the catalysts. These were prepared by ball milling to avoid the reflection of light to a maximum extent. Energy dispersive X-ray (EDX) analysis was used in conjunction with scanning electron microscopy (Cambridge instruments) to detect the dopants and other elements in the titania samples.

\subsection{Photocatalytic evaluation}

Photocatalysis was carried out in sunlight between 11 
$\mathrm{AM}$ and $2 \mathrm{PM}$ at Bangalore city $\left(13^{\circ} 00.57^{\prime} \mathrm{N}\right.$ and $77^{\circ} 34.15^{\prime}$ E) during the summer. The average solar intensity was 75.3 $\mathrm{mW} / \mathrm{cm}^{2}$. No steps were taken to maintain the intensity of sunlight during subsequent reactions. The reactor vessel had an exposure area of $176.62 \mathrm{~cm}^{2}$ into which the light was directly focused. The presence of oxygen was necessary for all the photoreactions since no degradation occurred in its absence.

The extent of mutagen degradation was studied by withdrawing $10 \mathrm{ml}$ of the treated sample at $10 \mathrm{~min}$ intervals for analysis. The UV-Vis spectra of these samples were recorded using a UV-Vis spectrophotometer (Shimadzu 1650PC UV-Vis spectrophotometer). The residual concentration of the EtBr in each of these samples was estimated from standard calibration curves of absorbance versus concentration of $\mathrm{EtBr}$ at $\lambda_{\max }=286 \mathrm{~nm}$. The rate of elimination of the proposed mutagen was evaluated using different experimental conditions and with various catalysts such as nano- $\mathrm{TiO}_{2}$ (synthesized), commercially available $\mathrm{TiO}_{2}$ (Degussa $\mathrm{P}-25$ ), and $\mathrm{Zr}$-doped $\mathrm{TiO}_{2}$ (range of dopant concentrations) and the results are listed in Table 1 . The difference in catalytic activity of the catalysts was calculated as follows: Catalytic efficiency $=k / C_{\text {catalyst }}$, where $k$ is the rate constant of the reaction obtained by the slope of $C / C_{0}$, where $C$ is the concentration of the dye obtained after an irradiation time period ' $t$ ' and $C_{0}$ is the initial concentration of the dye while $C_{\text {catalyst }}$ is the concentration of the catalyst. The salmonella reversion assay was conducted using the plate incorporation procedure, as described by Refs. [1,2].

\section{Results and discussion}

\subsection{XRD analysis}

The intensities and $d$ spacing of the $4 \% \mathrm{Zr}$-doped $\mathrm{TiO}_{2}$ patterns shown in Fig. 1(a) are in complete agreement with that of the anatase phase- $\mathrm{TiO}_{2}[26]$. The $100 \%$ line at a $d$-spacing of 3.5 indicates an unchanged phase of anatase compared to undoped $\mathrm{TiO}_{2}$ [25]. No peaks were present that correspond to a rutile phase. The powders do not show any significant peaks that correspond to the metal $(\mathrm{Zr})$ atom or the metal oxides (oxides of zirconium). No peaks were found that indicate the existence of any different phase that coexists in the doped sample. The XRD peaks of the (101), (200), and (004) crystal planes of anatase were selected to determine the lattice parameters. This corresponds to 27.62 $\mathrm{nm}$ with a unit cell parameter $a$ of $0.37857 \mathrm{~nm}$ and a cell volume of $0.13727 \mathrm{~nm}^{3}$ against a crystallite size of 21.43 $\mathrm{nm}$, an $a$ of $0.37843 \mathrm{~nm}$ and a cell volume of $0.13683 \mathrm{~nm}^{3}$ for the undoped sample. A slight shift in the $d$-spacing with an observable change in cell volume indicates the incorporation of dopants into the $\mathrm{TiO}_{2}$ lattice.
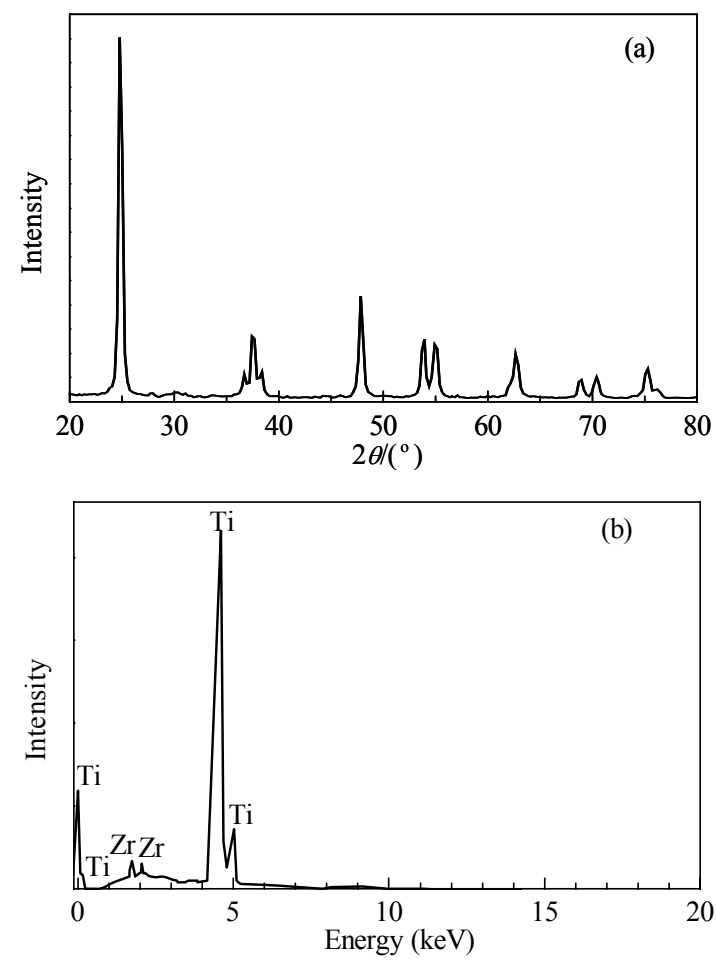

Fig. 1. XRD pattern (a) and EDX pattern (b) of the $4 \% \mathrm{Zr}$-doped titania.

The increase in cell volume can be attributed to the increase in ionic radii from $0.065 \mathrm{~nm}\left(\mathrm{Ti}^{4+}\right)$ to $0.072 \mathrm{~nm}\left(\mathrm{Zr}^{4+}\right)$ upon doping. However, an EDX analysis of the 4\% doped sample substantiated the presence of $4.33 \% \mathrm{Zr}$ and this is shown in Fig. 1(b).

Since the XRD patterns of the catalysts with different dopant concentrations were similar (from $1 \%-4 \%$ ) with no characteristic reflections of the dopants, the XRD pattern of the most optimum concentration is shown. This is based on the critical value of the dispersion capacity wherein the significant peaks do not appear at values lower than that at which the oxides may become highly dispersed on the support without the formation of a separate crystalline phase.

The crystal lattice of $\mathrm{TiO}_{2}$ undergoes severe plastic deformation during the process of ball milling, which produces stresses and strains [27]. This creates a $\mathrm{TiO}_{2}$ crystal lattice distortion, which results in many defects within the $\mathrm{TiO}_{2}$ particles. These defects have a high lattice distortion energy and surface energy. This causes the activation energy for the diffusion of elements to decrease markedly, and allows for substantial atomic or ionic diffusion among the elements at room temperature. When the activity of the powder system is high enough during the ball milling process the collision between the balls and grains in the powder will result in an increase in the interface temperature, which will result in the incorporation of dopants. The process of pulverization results in the retention of the anatase phase in addition to the efficient incorporation of the metal ions into 
the $\mathrm{TiO}_{2}$ lattice.

\subsection{Surface morphology}

Micrographs of the powder samples were obtained using scanning (Fig. 2(a)) and transmission (Fig. 2(b)) electron
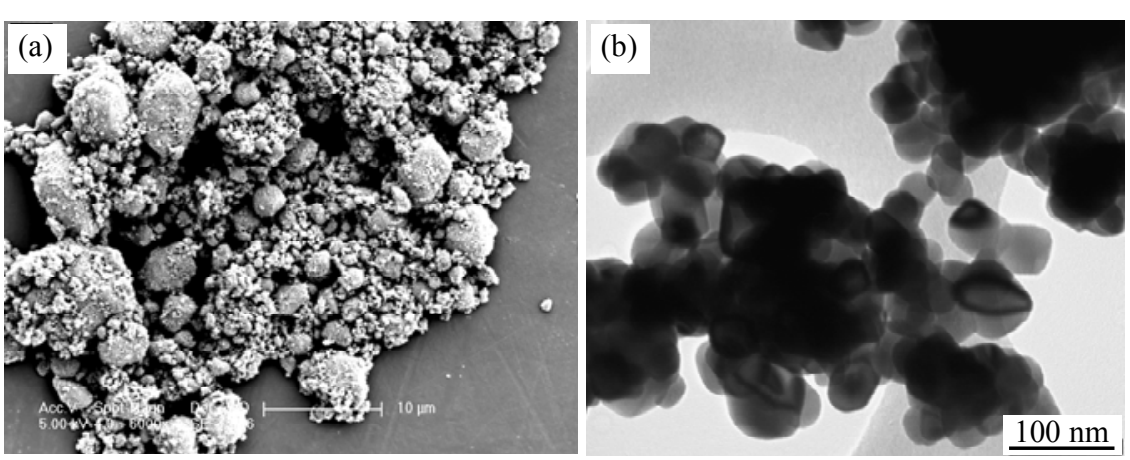

Fig. 2. SEM (a) and TEM (b) micrographs of the $4 \% \mathrm{Zr}$-doped $\mathrm{TiO}_{2}$.

\subsection{Spectral analysis}

Figure 3 shows the optical absorption spectra of the two catalysts. The sharp decrease in the spectrum of $\mathrm{TiO}_{2}$ at an absorption edge of $400 \mathrm{~nm}$ is assigned to the bandgap of pure anatase nano- $\mathrm{TiO}_{2}$. The doped sample (4\%) had distinct maxima and sharp bands (intense absorption) in the same region and the peak values did not change much. However, the optical absorption edge of the doped crystal shifted to a higher wavelength, indicating the extension of light absorption to visible range at wavelengths above 400 $\mathrm{nm}$. In the Zr-doped sample, the electronic transitions from the valence band to the dopant level or from the dopant level to the conduction band can effectively red shift the band edge absorption threshold. Furthermore, the electrons are affected by the presence of particle boundaries because of the geometrical constraints that exist in nanoparticles and they respond to changes in particle size by adjusting their energy [28]. The prediction that the size dependent contri-

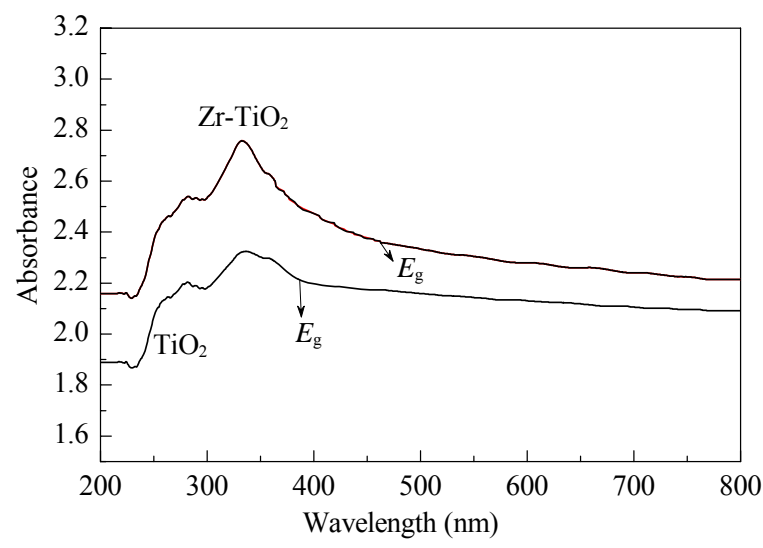

Fig. 3. Absorption spectra of the pure and $4 \% \mathrm{Zr}$-doped $\mathrm{TiO}_{2}$. microscopes. These micrographs show a substantial increase in grain size upon doping and they show doped titania particles in the lattice in comparison with undoped $\mathrm{TiO}_{2}$ [25]. The electron diffraction of the individual particles shows that they are nano and cubicular crystallites with average sizes of $25 \mathrm{~nm}$. bution to the energy gap $\left(E_{\mathrm{g}}\right)$ is simply proportional to $1 / r^{2}$ ( $r$ being the particle radius) is strongly supported by the observed red shift in the spectra of the doped sample [29]. There was a significant decrease in the bandgap energy from nearly $3.1 \mathrm{eV}$ to $\cong 2.7 \mathrm{eV}$. This agrees with the increase in crystallite size from $21.43 \mathrm{~nm}$ to $27.62 \mathrm{~nm}$ upon doping.

\subsection{Photoelimination}

The exponential decay of the mutagen during photodegradation is shown in Fig. 4 by a plot of $C / C_{0}$ versus time. The representative lines in the graph are as per the reaction conditions explained in Table 1. The presence or absence of

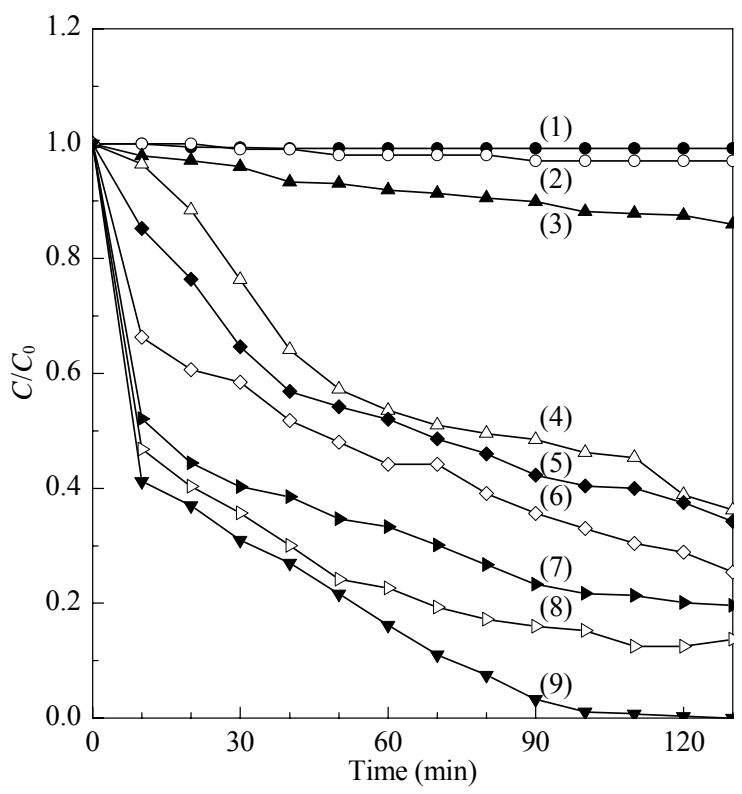

Fig. 4. Extent of photodegradation of the proposed mutagen. 
Table 1 Effect of different reaction parameters using $250 \mathrm{ml}$ of a 10 ppm EtBr solution for a comparative evaluation of the rate of elimination

\begin{tabular}{cccc}
\hline $\begin{array}{c}\text { Line repre- } \\
\text { sentation in } \\
\text { Fig. } 4\end{array}$ & Photocatalyst & $\begin{array}{c}\text { Irradiation } \\
\text { source }\end{array}$ & $\begin{array}{c}\text { Rate of } \\
\text { elimination } \\
\left(\mathrm{min}^{-1}\right)\end{array}$ \\
\hline$(1)$ & $\begin{array}{c}\text { presence/absence of catalyst } \\
\text { Nano- } \mathrm{TiO}_{2}\left(\text { absence of } \mathrm{O}_{2}\right)\end{array}$ & sunlight & $\begin{array}{c}\text { nil } \\
\text { negligible }\end{array}$ \\
$(2)$ & absence of catalyst & sunlight & 0.0070 \\
$(3)$ & presence of $\left.\mathrm{O}_{2}\right)$ & sunlight & 0.0107 \\
& Degussa $\mathrm{P}^{25}$ & sunlight & 0.0121 \\
$(4)$ & nano- $\mathrm{TiO}_{2}$ & sunlight & 0.0337 \\
$(5)$ & $1 \% / \mathrm{Zr}$-doped $\mathrm{TiO}_{2}$ & sunlight & 0.0478 \\
$(6)$ & $2 \% / \mathrm{Zr}$-doped $\mathrm{TiO}_{2}$ & sunlight & 0.0532 \\
$(7)$ & $3 \% / \mathrm{Zr}$-doped $\mathrm{TiO}_{2}$ & sunlight & 0.0600 \\
$(8)$ & $4 \% / \mathrm{Zr}$-doped $\mathrm{TiO}_{2}$ & & \\
$(9)$ & & &
\end{tabular}

the catalyst did not affect EtBr degradation in the dark. For a non-oxygenated photoreaction, the presence of a catalyst has no effect on dye degradation $[25,30]$ while the presence of oxygen causes degradation to some extent even without a catalyst. Therefore, all the other photocatalytic reactions were carried out in presence of oxygen.

The activity of the synthesized nano- $\mathrm{TiO}_{2}$ was 0.711 times higher than that of the commercially available Degussa P-25. A marked increase in degradation rate $(2.78$ times) was observed when nano- $\mathrm{TiO}_{2}$ was doped with $1 \%$ $\mathrm{Zr}$ and used for catalysis. The increase in dopant concentration from $1 \%$ to $4 \%$ results in an increase in catalytic activity by $2.7,3.9,4.3$, and 4.9 times, respectively. A $4 \%$ dopant concentration was thus determined to be optimum and beyond this the increase in dopant concentration was independent of the rate of elimination.

These results suggest that the optimum zirconium concentration in the $\mathrm{TiO}_{2}$ lattice results in an efficient separation of charge carriers. It is well known that photogenerated holes react with surface water to produce hydroxyl radicals and this depends on the competition between surface water oxidation by holes and electron hole recombination. The higher activity of the $4 \% \mathrm{Zr}$-doped sample can be attributed to the excess generation of $\mathrm{OH}^{-}$radicals and at this optimum concentration, the surface barrier becomes higher and the space charge region is extended leading to an efficient separation of electrons and holes. The possibility of trapped charge carrier recombination through quantum tunneling could increase because of the lack of driving force to separate them. For dopant concentrations higher than $4 \%$, the space charge region becomes very narrow and the penetration depth of light into $\mathrm{TiO}_{2}$ greatly exceeds the thickness of the space charged layer, which increases the recombination rate of electrons and holes. The concentration of the dopant ions becomes optimum when the thickness of the space charge layer equals the light penetration depth.

Therefore, $\mathrm{Zr}$ as a substitutional impurity is mainly responsible for the increase in photoactivity. Although pulverization has an advantage in terms of the incorporation of metal ions and the retention of the nanophase and structure, it is known to adversely affect the photocatalytic effect for other metal ions that were doped in titania.

The lower bandgap energy obtained after a decrease from $3.1 \mathrm{eV}$ to $\cong 2.7 \mathrm{eV}$ (because of the creation of new dopant levels) can respond to visible light and appears to be very important for the explanation of the substantial increase in the activity of the doped titania in visible light. The radius of $\mathrm{Zr}^{4+}(0.072 \mathrm{~nm})$ is larger than that of $\mathrm{Ti}^{4+}(0.065 \mathrm{~nm})$. Because of steric reasons, the formation of complex defects comprising $\mathrm{Zr}$ atoms and an oxygen vacancy in close proximity is energetically more favorable and cannot be ruled out as the reason for increased photoactivity. In Kröger and Vink notation, the probable chemical reaction can be represented in a favorable way. $\mathrm{ZrO}_{2} \rightarrow \mathrm{Zr}_{\mathrm{Ti}}{ }^{+}+\mathrm{V}_{\mathrm{O}}+$ $\mathrm{O}_{\mathrm{o}}+1 / 2 \mathrm{O}_{2}+2 \mathrm{e}^{-}$, where $\mathrm{Zr}_{\mathrm{Ti}}{ }^{\prime}$ is the $\mathrm{Zr}$ ion at a Ti lattice site with a single charge deficiency, $V_{\ddot{O}}$ is a doubly ionized oxygen vacancy, $\mathrm{O}_{\mathrm{o}}$ is an oxygen ion in the normal lattice site where the concentration of the intrinsic defect $\left(\mathrm{V}_{\ddot{\mathrm{O}}}\right)$ becomes equal to the concentration of the extrinsic impurity. Furthermore, the higher photocatalytic activity of $\mathrm{Zr}$-doped $\mathrm{TiO}_{2}$ can also be attributed to a gradual upward shift of the conduction bands, which results in a modification of the electronic structure. This results in a stronger reduction ability for the photogenerated electrons and appears to be an additional factor in the enhanced photoactivity.

The elimination of $\mathrm{EtBr}$ (initiated by the rupture of the phenanthridinium ring) [5] was $100 \%$ within $120 \mathrm{~min}$ of exposure to sunlight in the presence of modified (4\%) titania. It had a catalytic efficiency 4.9 times more than that of the undoped powder in a $10 \mathrm{ppm}$ solution of $250 \mathrm{ml} \mathrm{EtBr}$.

The solution treated above was subjected to an Ames test [3]. The treated EtBr solution was investigated for its ability to stimulate back mutations and thus increase the induced revertants in addition to the spontaneous revertants. The mutagen that was not treated gave a reproducible and prominent two fold increase in the number of revertant colonies whereas the treated sample did not result in an increase in the number of revertant colonies, which confirms the non-mutagenicity or loss of intercalating property of the mutagen.

\section{Conclusions}

The incorporation of $\mathrm{Zr}$ into the $\mathrm{TiO}_{2}$ lattice by pulverization results in substitutional impurities with the retention of the nanocrystalline and anatase phases, which fine tunes the electronic properties of $\mathrm{TiO}_{2}$ resulting in the better utiliza- 
tion of a much broader spectrum of solar radiation. The studied composition shows that the creation of midbands for effective charge separation together with the narrowing of the bandgap to within the visible range facilitates an increase in catalytic activity by 4.9 times leading to the complete degradation of an EtBr solution (10 ppm) within 120 min of exposure to sunlight. An Ames test confirmed the non-mutagenicity of the treated sample. Ethidium bromide, being a derivative of phenanthridium, easily succumbs to the sunlight induced reactive oxygen species that is generated by the modified titania catalysts. We thus investigated a highly efficient procedure for the synthesis of zirconium-doped $\mathrm{TiO}_{2}$ and its application as a visible light induced photocatalyst for the demutagenesis of mutagens.

\section{Acknowledgements}

The authors wish to acknowledge Visvesvaraya Technological University, Belgaum, and the Center for Emerging Technologies, Jain University, Bangalore as well as Naveen, Jain University for their support and for a Grant-in-aid to carry out the research work described in this paper.

\section{References}

1 Maron D M, Ames B N. Mut Res, 1983, 113: 173

2 Mortelmans K, Zeiger E. Mut Res, 2000, 455: 29

3 Ames B N, McCann J, Yamasaki E. Mutat Res, 1975, 31: 347

4 Mathur N, Bhatnagar P, Bakre P. Appl Ecol Env Res, 2005, 4: 111

5 Adan C, Bahamonde A, Martinez-Arieas A, Fernandez-Garcia M, Perez-Estrada L A, Malato S. Catal Today, 2007, 129: 79

6 Faisal M, Abu Tariq M, Muneer M. Dyes Pigm, 2007, 72: 233

7 Suzuki H, Amano T, Toyooka T, Ibuki Y. Environ Sci Technol, 2008, 42: 8076

8 Hengen P N. Trends Biochem Sci, 1994, 19: 257

9 Lunn G, Sansone E B. Anal Biochem, 1987, 162: 453
10 Fox M A, Dulay M T. Chem Rev, 1993, 93: 341

11 Pelizzeti E, Minero C. Electrochim Acta, 1993, 38: 47

12 Kormann C, Bahnemann D W, Hoffmann M R. J Photochem Photobiol A, 1989, 48: 161

13 Muruganandham M, Swaminathan M. Dyes Pigm, 2006, 68: 133

14 Sonawane R S, Mohan Dongare K. J Mol Catal A, 2006, 243: 68

15 Toor A P, Verma A, Jotshi C K, Bajpai P K, Singh V. Dyes Pigm, 2006, 68: 53

16 da Silva C G, Faria J L. J Photochem Photobiol A, 2003, 155: 133

$17 \mathrm{Hu}$ C, Lan Y, Qu J, Hu X, Wang A. J Phys Chem B, 2006, 110: 4066

18 Seery M K, George R, Floris P, Pillai S C. J Photochem Photobiol A, 2007, 189: 258

19 Devi L G, Murthy B N, Kumar S G. Chemosphere, 2009, 76: 1163

20 Sakulkharmarnethai S, Kitiyanan A, Yoshikawa S. J Ceram Process Res, 2006, 7: 10

21 Liu S, Yu J, Jaroniec M. J Am Chem Soc, 2010, 132: 11914

22 Liu S, Yu J, Mann S. J Phys Chem C, 2009, 113: 10712

23 Lukac J, Klementova M, Bezdicka P, Bakardjieva S, Subrt J, Szatmary L, bastl Z, Jirkovsky J. Appl Catal B, 2007, 74: 83

24 Gao B, Lim T M, Subagio D P, Lim T T. Appl Catal A, 2010, 375: 107

25 Swetha S, Santhosh S M, Balakrishna R G. Photochem Photobiol, 2010, 86: 628

26 Henry N F M, Lonsdale K. International Tables for X-Ray Crystallography. Birmingham: Kynoch Press, 1952. 151

27 Chen S, Chen L, Gao S, Cao G. Chem Phys Lett, 2005, 413: 404

28 Abrams B L, Wilcoxon J P. Crit Rev Solid State Mater Sci, 2005, 30: 153

29 Aghababazadeh R, Mirhabibi A R, Brydson R, Salehpour Z. Proceedings of 1 st International Conference on Nanostructured Materials and Nanocomposites. India: Kottayam, 2009

30 Devi L G, Balakrishna R G. Pol J Chem, 2005, 79: 915 